\title{
Improved Diagnosis of Duchenne/Becker Muscular Dystrophy
}

\author{
Alan H. Beggs and Louis M. Kunkel \\ Division of Genetics and Mental Retardation Center, The Children's Hospital, Department of Pediatrics, Harvard Medical School, and \\ Howard Hughes Medical Institute, Boston, Massachusetts 02115
}

\begin{abstract}
Molecular genetics has revolutionized the way one should consider a patient with muscular dystrophy. The purpose of this Perspectives article is to set the parameters by which physicians may judge their neuromuscular patients in the context of recent advances in the understanding of both genetic and biochemical aspects of muscular dystrophy. We will first review some of the progress that has occurred over the past 5 years. This will illustrate how advances at the basic science level have led directly to powerful new diagnostic tests and, hence, to a new "molecular definition" of Duchenne and Becker muscular dystrophies (DMD and BMD). ${ }^{1}$ After discussing the strengths and weaknesses and appropriate use of these tests, we will end with specific examples of their use in a clinical setting. We hope this review will aid in the rapid transition of these tests from the research laboratory to routine clinical use.
\end{abstract}

\section{Background}

Duchenne muscular dystrophy is a severe, progressive, muscle-wasting disorder that leads to loss of ambulation by 11-12 yr of age and, eventually, death by the third decade, often due to pulmonary insufficiency (1-3). BMD is a milder form in which a similar clinical course is followed but at a much slower and more variable rate (3). These patients generally become wheelchair-bound sometime after $15 \mathrm{yr}$ and some may remain ambulatory into their $60 \mathrm{~s}$. The incidence of DMD/BMD is extremely high for a genetic disease ( 1 in 3,500 male births with DMD being about 10 times more common than BMD), and it has been estimated that up to one-third of cases represent new mutations (2). The unequal sex distribution provided the first clue to the genetic location of these diseases on the human X chromosome. Careful cytogenetic analysis of several unusual patients led to the finding that abnormalities (deletions and translocations) of the middle of the short arm of the $X(X p 21)$ could result in muscular dystrophy $(4,5)$. Once a tentative location was known, linkage studies were undertaken using randomly cloned DNA probes from this region of the chromosome (6). These reports not only confirmed the local-

Address reprint requests to Dr. Kunkel, Division of Genetics, The Children's Hospital, 300 Longwood Avenue, Boston, MA 02115.

Received for publication 8 December 1989.

1. Abbreviations used in this paper: BMD and DMD, Becker and Duchenne muscular dystrophies; CPK, creatine phosphokinase; PCR, polymerase chain reaction; RFLP, restriction fragment length polymorphism.

J. Clin. Invest.

(c) The American Society for Clinical Investigation, Inc. 0021-9738/90/03/0613/07 $\$ 2.00$

Volume 85, March 1990, 613-619 ization of the DMD gene to $\mathrm{Xp} 21$, but they also provided the first evidence that DMD and BMD are actually allelic disorders; i.e., they are both caused by different mutations to the same gene (7).

After an intensive effort by a number of laboratories, parts of the actual gene itself were first isolated by two groups, within 6 months of each other, in late 1986 and early 1987 (8, 9 ). When these early genomic DNA probes were used to examine DNA from patients with DMD and BMD, it was found that up to $5 \%$ had gene deletions (10-12). However, linkage analysis in families without detectable deletions suggested that mutations causing DMD could occur at great distances on either side of the cloned probes $(13,14)$. This apparent paradox was resolved when the entire cDNA was cloned (15). The 14-kilobase (kb) transcript was found to be encoded for by more than 70 exons spread over nearly $2,500 \mathrm{~kb}$ of genomic DNA (15-17). This enormous size presumably explains the high mutation rate since the gene presents such a large target (sizes for "average genes" have a range of 3-300 kb).

Pieces of the cDNA could now be used as probes to specifically examine all of the exons by Southern blot analysis, revealing that about $65 \%$ of DMD and BMD patients had deletions or duplications of one or more exons of this gene $(15,18$, 19). The cDNA was also used to produce fusion proteins of the DMD gene product in bacteria (20). Antisera raised against these products recognized a large $400-\mathrm{kD}$, muscle-specific protein that was named "dystrophin" (20). Sequence analysis of the cDNA had suggested that dystrophin was a component of the membrane cytoskeleton inasmuch as it was related to two other cytoskeletal components, $\alpha$-actinin and spectrin (21-23). This prediction was supported by the immunologic localization of dystrophin to the inner face of the myofiber cell membrane (24-27). When antisera were used to examine dystrophin in muscle biopsies from patients with various neuromuscular diseases, it was found that patients with DMD invariably had absence of detectable dystrophin, whereas those with BMD had dystrophin of altered size and/or quantity (26, $28,29)$. Normal controls and the vast majority of patients with other neuromuscular diseases had normal-appearing dystrophin. Thus, this progress generated the tools to provide accurate, unequivocal diagnoses as well as genetic testing and prenatal diagnosis for the majority of patients with DMD and BMD.

The new molecular tests for DMD/BMD fall into two groups: those that examine dystrophin protein (western blotting and immunofluorescence) and those that study the gene (Southern blotting with cDNA probes, polymerase chain reaction [PCR] (30), and restriction fragment length polymorphism [RFLP]-based linkage studies). Each test has its strengths and weaknesses and is best used under specific circumstances as outlined below. 


\section{Dystrophin immunoblotting}

The only prerequisites for direct detection of dystrophin are that appropriate tissue (e.g., skeletal, cardiac, or smooth muscle) be obtained and immediately frozen and stored at $-70^{\circ} \mathrm{C}$. In many cases, preexisting biopsies $10 \mathrm{yr}$ old or older have been successfully tested provided that they have never gone through a thaw-freeze cycle. Either needle or open biopsies are adequate in that only $10-15 \mathrm{mg}$ of tissue is needed. To perform the test, the specimen is weighed and solubilized in SDS buffer at $-20^{\circ} \mathrm{C}$ and then separated by electrophoresis in SDS denaturing polyacrylamide gradient gels (28). After transferring the proteins to a nitrocellulose membrane, the remaining gel is stained and examined for residual myosin. This provides an internal control for degradation and equal loading of lanes (28). It also controls for tissue type since myosin, like dystrophin, is a muscle-specific protein. Dystrophin is visualized by successively incubating the nitrocellulose membrane in sheep anti-dystrophin and immunoperoxidase-conjugated rabbit anti-sheep IgG, followed by developing for peroxidase (28). By comparison to adjacent control lanes either visually or by densitometry, the quality (size) and quantity of dystrophin are assessed (Fig. $1 \mathrm{~A}$ ). All told, this process takes $3 \mathrm{~d}$ from start to finish.

In general, the complete absence of dystrophin is predictive of DMD (> 99\% accuracy), whereas the presence of larger- or smaller-sized, and/or the reduced abundance of, dystrophin establishes a diagnosis of BMD ( $>95 \%$ accuracy) $(28,29)$. Patients with $<20 \%$ normal levels of dystrophin often exhibit an intermediate phenotype, becoming wheelchair bound be- tween the ages of 13 and 20 yr (so-called "outliers") (31). Although the test is still in its infancy, our laboratory's experience with over 400 biopsies has revealed only two "DMD" cases with normal-appearing dystrophin. One of these cases was sporadic but the other had a history of consanguinity, suggesting that these patients represented a rare autosomal recessive variant of muscular dystrophy (32). Two other apparent exceptions were two patients clinically diagnosed as BMD but who had no detectable dystrophin. Subsequent DNA analysis showed that both had large deletions encompassing the region of dystrophin used to raise the antibodies. In fact, when these patients were later retested with antisera raised against a different part of the molecule, dystrophin was detected, thus confirming the clinical diagnosis of BMD at the molecular level and underscoring the need to use multiple antisera for some patients (33).

Although immunoblotting is clearly a sensitive diagnostic test for DMD and BMD in boys, it is not capable of detecting the small reductions of dystrophin levels in most DMD carrier females. An alternate approach is to culture myoblasts from suspected carriers and perform dystrophin analysis on clonal populations of cells that had been induced to fuse into myotubes (34). Since females randomly inactivate one $X$ chromosome in each cell, roughly half of colonies from a DMD carrier are expected to express dystrophin while the other half are not. On the one hand, although this method is time-consuming and expensive, it may be the most sensitive approach to carrier detection for DMD and BMD. On the other hand, our limited experience with manifesting carriers suggests that dystrophin

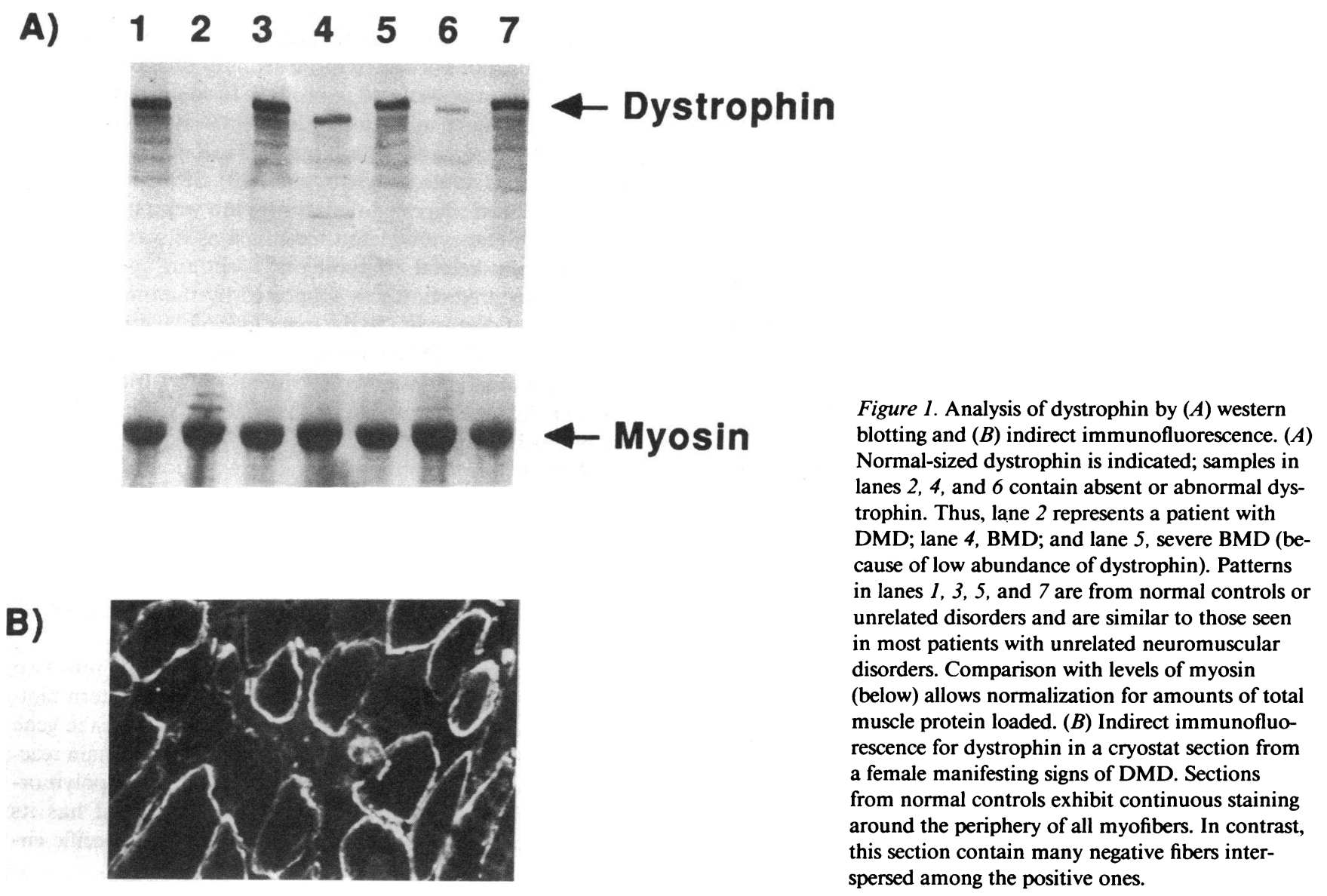


levels low enough to cause substantial weakness often are detectable as abnormal. Furthermore, many BMD carriers are apparently detectable on western blot because their muscle often contains both normal and abnormally sized dystrophin.

\section{Immunohistochemistry}

Indirect immunofluorescence on frozen sections of muscle provides a complementary approach to western blotting for dystrophin analysis. In normal individuals, dystrophin immunostaining is detected as a homogeneous ring around the periphery of all muscle fibers (24-26). Muscle from DMD patients has no detectable staining, but in patients with BMD, the staining may range from almost normal to patchy and significantly lighter (35). Although quite useful in males, the test is most useful for detecting female DMD carriers who often have patches of negative fibers among positive fibers owing to $\mathrm{X}$ chromosome inactivation (Fig. $1 B$ ). It should be noted, however, that a negative result (i.e., only positive fibers) is not sufficient to rule out carrier status in that it may simply reflect sampling error or nonrandom $X$ inactivation, perhaps due to selective loss of dystrophin-negative fibers. Limited experience suggests that those carriers with elevated creatine phosphokinase (CPK) levels generally have detectable, negatively staining fibers. Finally, immunofluorescence does not generally detect BMD carriers.

\section{Detection of dystrophin gene mutations at the DNA level}

Two methods, Southern blotting and the PCR, are currently in use to detect alterations of the dystrophin gene. DNA is isolated from 5-10 ml of peripheral blood collected in EDTA and Southern blots are prepared and probed with cDNA clones (Fig. $2 \mathrm{~A}$ ). In this way, restriction fragments containing each exon can be examined for duplication or deletion (up to seven different blots are necessary to cover the entire gene). For the $65 \%$ of DMD/BMD patients who have detectable mutations (deletions or duplications), this test confirms their diagnosis and allows for carrier detection and prenatal diagnosis for other at-risk relatives. It should be noted, however, that absence of a detectable abnormality is not sufficient to rule out these diagnoses. In families carrying a detectable mutation, carrier detection in females requires careful analysis of Southern blots to distinguish one versus two copies of the gene in the deleted region (36). Prenatal diagnosis can be done on DNA from either chorionic villus sampling- or amniocentesis-derived cells (36). Because of the high mutation rate, mothers who are apparently not carriers (based on analysis of DNA from lymphocytes) are still offered prenatal diagnosis to guard against the possibility that they may be germline mosaics (37-39) (e.g., only some of their cells have the mutation which occurred during fetal development).

Since Southern blotting with cDNA probes allows nearly exact determination of missing or duplicated exons, some predictions can be made concerning the severity of a patient's disease (40). If the mutation introduces a frameshift of protein translation, little or no functional dystrophin is made resulting in DMD. BMD, in contrast, usually results from "in-frame" mutations that allow production of an internally deleted or duplicated partially functional protein. This correlation holds true for $\sim 92 \%$ of cases (41), with mutations at the $5^{\prime}$ end of the gene being one notable exception $(41,42)$. Because of these exceptions, protein studies are generally best for accurate prognostic determinations.
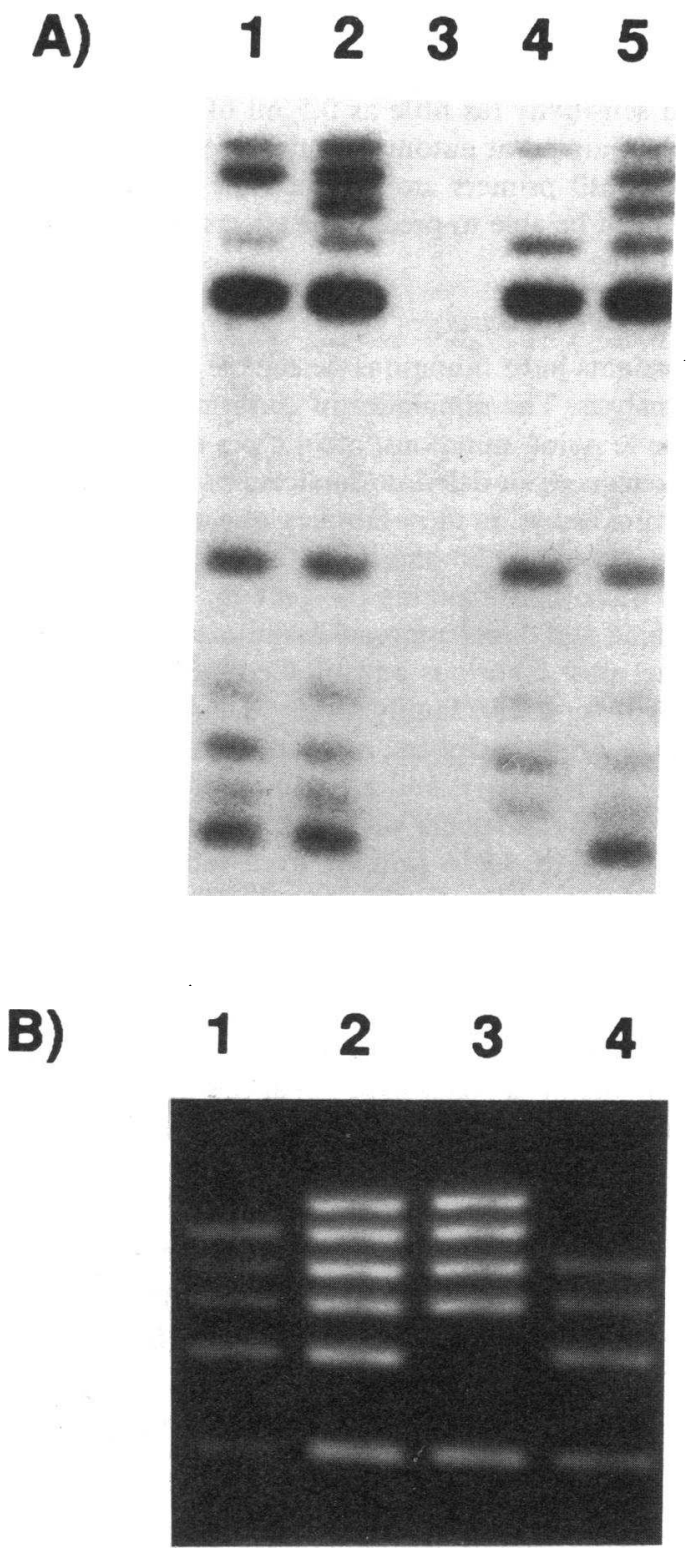

Figure 2. DNA-based analysis of mutations of the dystrophin gene. (A) Portion of an autoradiograph showing Southern blot analysis of DNA from male patients with muscle weakness. DNA was digested with HindIII and the filter was probed with the dystrophin CDNA clone 9-10. Each band represents hybridization of a different exon contained in the cDNA probe. Patients with deletions (lanes 1,3 , and 4 ) are missing one or more bands relative to the pattern in a normal male (lane 5). (B) Multiplex PCR analysis of six dystrophin gene exons as described by Chamberlain et al. (43). Lane 2 shows the normal pattern and patients in lanes 1,3 , and 4 all have deletions.

An early observation was that dystrophin gene deletions were preferentially found within one of two hotspot regions at the $5^{\prime}$ end and at $7-8 \mathrm{~kb}$ on the cDNA $(15,18)$. As a result of this clustering, the majority of deletions can be detected by examining only a subset of exons. Multiplex PCR analysis takes advantage of this fact resulting in extremely rapid screening for deletions (Fig. $2 \mathrm{~B}$ ). Using two mixtures of primers that amplify nine exons each, over $98 \%$ of cDNA-detectable deletions can now be identified by PCR (43, Beggs, 
A. H., and L. M. Kunkel, unpublished data). The primary advantages over Southern blotting are speed (1-2 d compared to 1-2 wk) and sensitivity (as little as $0.5 \mathrm{ml}$ of blood), and current research is aimed at automating this procedure even more. However, until primers are designed for many more exons, PCR will not be able to predict the effects of deletions on the reading frame.

\section{RFLP-based linkage analysis}

Only $65 \%$ of patients have mutations detectable by Southern blot or PCR analysis. The remainder of confirmed cases are presumably due to point mutations, other types of alterations to noncoding sequences, or deletion/duplications of exons not detected by current assays. In these families, one must resort to linkage analysis employing Southern blotting and determination of RFLPs within and flanking the gene $(6,7)$. With the advent of the rapid and direct approaches outlined above, this has become the most laborious and time-consuming procedure. In cases with a positive family history, DNA is obtained from the relevant family members. As many as seven or eight individuals may be necessary, and a common problem is the absence of key family members who have either died or are unavailable for analysis. DNA samples from each individual are cleaved with a series of restriction enzymes that define the particular alleles detected by a cloned DNA segment. To be "informative," a probe must recognize a restriction site that is polymorphic in the family being studied. By correlating the inheritance pattern of these RFLPs with the inheritance of the disease, one can identify a "haplotype" of alleles that identifies the chromosome carrying a mutation. One caveat is that since the mutation itself is not identified, genetic recombination between the mutation and a RFLP-defined locus may abolish the association (13). To identify these events, it is necessary to follow RFLPs flanking the gene as well as markers within the gene itself. Thus, as many as 20 probe/allele combinations may need to be tested in each family member. This analysis leads to probabilistic estimates of the likelihood that a given individual has inherited the chromosome carrying a mutation.

As more sequence data become available, PCR-based assays are being developed thus allowing rapid allele determination for many of the more informative RFLPs (44). A recent development is the finding that short tandem repeats (e.g., CACA $\cdots$ ) tend to be highly polymorphic in repeat number (45). The resulting size variation is detectable as differences in the mobility of PCR products encompassing these regions. Recently, we and others have developed PCR assays to detect variation of one such repeat at the $3^{\prime}$ end of the dystrophin gene $(46,47)$. In the future, multiplex PCR assays for this and other similar polymorphisms will undoubtedly make linkage analysis much faster and simpler.

A protocol for "molecular diagnosis" of muscular dystrophy Fig. 3 outlines the general protocol that we recommend when working up a patient with newly diagnosed muscle weakness. Of course, this entire discussion is predicated on the assumption that a complete neuromuscular workup has been performed, including CPK testing and muscle biopsy. Protein analysis is performed first to establish or rule out a diagnosis of DMD or BMD. Western blot analysis is the method of choice for boys and immunofluorescence for girls. In the event that

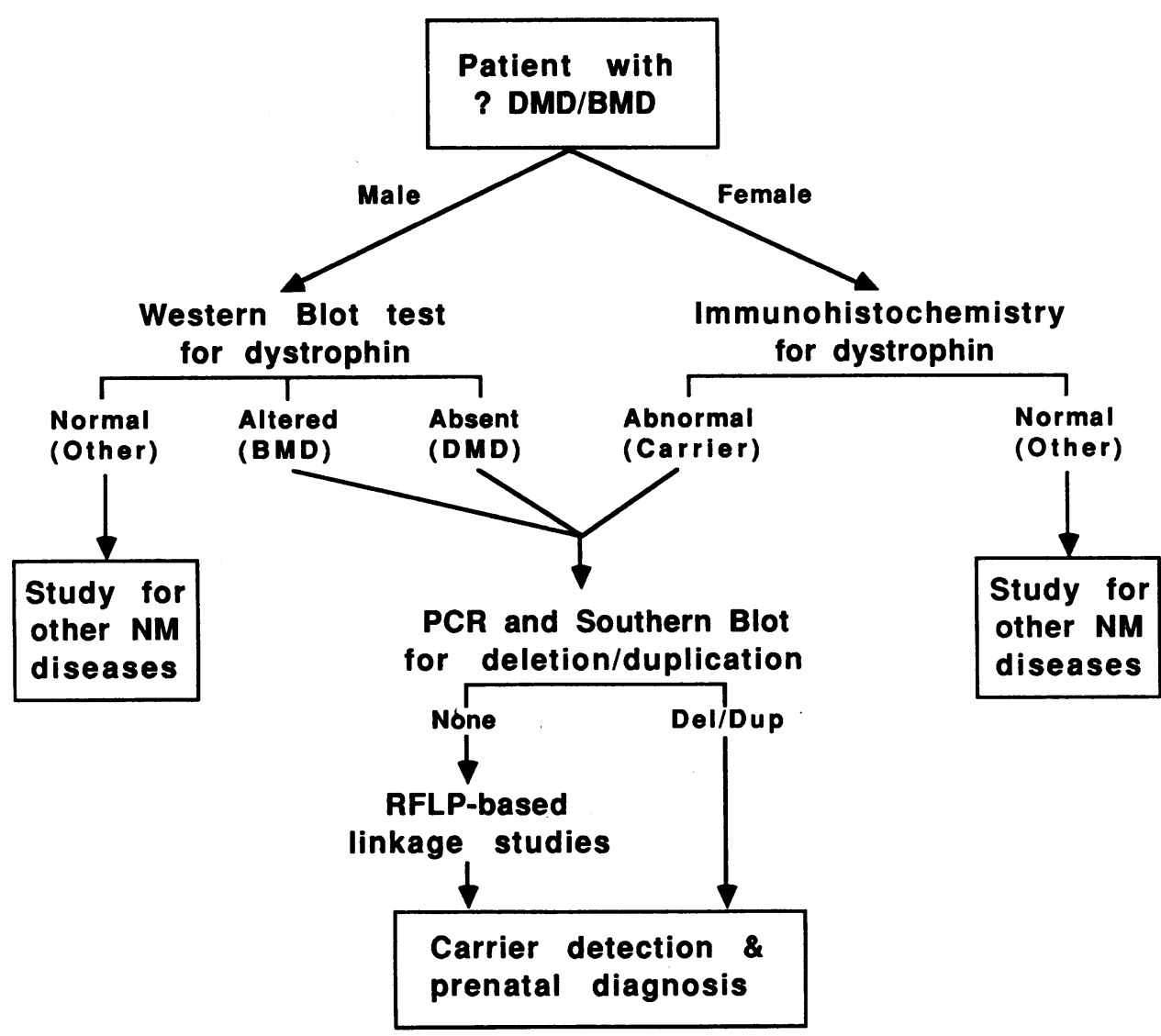

Figure 3. Flow diagram illustrating the protocol recommended to establish a "molecular diagnosis" of DMD or BMD. 
dystrophin abnormalities are found, DNA analysis is performed, first by PCR, and then by Southern blot if PCR did not detect a deletion. If a muscle biopsy is not available, DNA analysis alone can be performed, but it should be remembered that absence of a detectable mutation does not rule out a diagnosis of DMD/BMD. In cases without detectable mutations, linkage studies can be done if counseling is needed and there is appropriate family structure; however, it should be remembered that this analysis is based on the assumption of a firm clinical diagnosis.

Currently, DNA studies are offered by many of the DNA diagnostic laboratories that are springing up at major medical centers. Until now, dystrophin testing has been available only through several research laboratories on an informal basis, however this is changing rapidly as more diagnostic laboratories begin to offer these services. Thus, it is our belief that, in future, all muscle biopsies should have at least one piece of tissue flash frozen in isopentane at $-70^{\circ} \mathrm{C}$ to allow for eventual protein testing of dystrophin (or any other tests that may be developed).

The last few years have seen many exciting advances in our understanding of the underlying defects in DMD and BMD. It is extremely gratifying to see the rapidity with which this knowledge has been used to directly benefit patients and their families. We hope that these advances will soon lead to the development of rational and effective therapies for these devastating diseases.

\section{Illustrative case histories}

Case 1. The patient is a 4-yr-old boy with a waddling gait and difficulty climbing stairs. He walked at $10 \mathrm{mo}$. The physical examination revealed him to have mild proximal muscle weakness including a positive Gower's sign. The laboratory findings were significant for a CPK level > 5,000 (normal $<200$ ). Family history was negative for neuromuscular disease. The patient had two asymptomatic siblings. His $10-y r-$ old brother had a CPK level within the normal range, and his 16-yr-old sister's CPK level was slightly elevated. His mother's CPK level was normal. The patient's muscle biopsy was consistent with muscular dystrophy and a clinical diagnosis of Duchenne muscular dystrophy was made.

Question: What can be done to confirm a diagnosis at this early stage, and are carrier detection and prenatal diagnosis possible for the patient's mother and sister? Answer: To establish a diagnosis, a frozen piece of the preexisting muscle biopsy was sent for dystrophin testing. The absence of detectable dystrophin confirmed a diagnosis of DMD (e.g., as in Fig. $1 A$, lane 2). PCR testing of the patient's DNA revealed a deletion within the dystrophin gene (e.g., Fig. $2 B$, lane 4). Subsequent Southern blot analysis on DNA from the patient (e.g., Fig. $2 A$, lane 4) and his mother and sister confirmed the deletion and revealed that both women had one normal and one deleted copy of the dystrophin gene (females not shown). On the basis of these findings, both were counseled that they were indeed carriers and that upon future pregnancies each could be offered prenatal diagnosis.

Case 2. This patient is an 8 -yr-old boy who presented with a recent history of toe walking and intermittent leg pain. He had previously normal motor development and was active in sports. The physical examination was remarkable for calf hypertrophy, difficulty with heel walking, and tightened Achilles tendons. Family history was remarkable for calf hypertrophy in two maternal aunts and an uncle. The uncle had weakness of foot dorsiflexion but was still able to remain active as a tennis professional. The patient's CPK level was 20,000 (normal $<200$ ) and a muscle biopsy showed myopathic changes. Differential diagnosis included X-linked muscular dystrophies (i.e., Becker or Emery-Dreifus muscular dystrophy), autosomal recessive limb-girdle dystrophy, and subacute dermatomyositis/polymyositis.

Question: Can the diagnosis be definitively established? Answer: Dystrophin testing revealed that the patient's muscle contained dystrophin of $\sim 380 \mathrm{kD}$ (normal $400 \mathrm{kD}$ ) and near-normal abundance (e.g., Fig. $1 A$, lane 4 ). PCR testing detected a deletion (e.g., Fig. $2 B$, lane 1 ) which, upon Southern blot analysis, was confirmed as being "in-frame" (not shown). This deletion was also found in the two aunts and one uncle with calf hypertrophy. Genetic counseling was offered for any future pregnancies.

Case 3. The patient is a 28-yr-old woman with a history of progressive muscle weakness. She was a poor runner as a young child and by age $8 \mathrm{yr}$ she began to have difficulty climbing steps and arising from a chair. By age 17 she could barely raise her arms over her head. On physical examination, she was noted to have a waddling gait, a positive Gower's maneuver, lumbar lordosis, and marked hypertrophy of her calves. She has an identical twin sister and five other siblings, none of whom have any symptoms of muscle disease. The twin sister, however, has a 7-yr-old son with clinical and laboratory findings consistent with the diagnosis of Duchenne dystrophy.

Question: Is this patient a manifesting carrier for DMD, or does she suffer from some unrelated disorder? Answer: Immunofluorescence for dystrophin in cryostat sections from a muscle biopsy revealed patches of dystrophin-negative fibers indicative of the carrier state (e.g., Fig. 1 B). Interestingly, immunofluorescence of the patient's identical twin's muscle was normal. The occurrence of one manifesting carrier in twin combinations has been reported previously and may involve unequal X-chromosome inactivation as a direct result of the twinning process (48). Because PCR deletion analysis of DNA from the nephew failed to detect a deletion, RFLP-based linkage studies were performed so prenatal diagnosis could be offered in future pregnancies.

Case 4. This patient is a 6-yr-old boy with a history of severe limb girdle weakness of longstanding duration. His physical examination findings were significant for marked weakness of the shoulder and hip girdles. His calves were not hypertrophied. Family history was negative for neuromuscular disorders. The CPK levels were elevated on two occasions: the values were 450 and 534 (normal $<200$ ). Electromyogram and muscle biopsy results were consistent with muscular dystrophy.

Question: Does the patient have sporadic DMD/BMD or some other form of muscular dystrophy (e.g., limb-girdle or Emery-Dreifus)? Answer: Dystrophin testing by western blot revealed dystrophin of normal size and abundance (e.g., Fig. 1 $A$, lane 5). The presence of normal dystrophin effectively rules out a diagnosis of DMD/BMD, suggesting that the patient has autosomal recessive limb-girdle dystrophy or perhaps the more rare autosomal recessive form of Duchenne-type muscular dystrophy. The patient's DNA was banked for future studies as more disease genes become identified. The parents were counseled that each subsequent pregnancy carried a $25 \%$ recurrence 
risk regardless of fetal sex. In relation to potential therapies, this patient might not be expected to respond to treatments designed specifically for DMD/BMD.

Case 5. This is a hypothetical case but could easily be a common situation in the future. Proband is a 3-wk-old male. As part of a newborn screening program, he is found to have an elevated CPK level. Physical examination gives unremarkable findings, and there is no family history of muscle weakness. A repeat CPK test result is also markedly elevated.

Question: Could testing for dystrophin help this family? Answer: Western blotting revealed absence of detectable dystrophin in muscle from this patient, thus establishing a diagnosis of DMD at a time when his parents were planning another pregnancy. PCR analysis detected a deletion in the boy and Southern blotting confirmed this; however, his mother had two normal copies of the dystrophin gene in DNA from her peripheral blood. Because there is a significant probability that she may be germline mosaic, prenatal diagnosis was still offered for all future pregnancies.

\section{Acknowledgments}

We thank Linda Specht and Jami Levine for their critical reading of this manuscript and Eric Hoffman and the other members of our laboratory for helpful discussions.

This work was supported by grants from the National Institutes of Health (NS-23740 and HD-18658) and the Muscular Dystrophy Association. Dr. Kunkel is an Associate Investigator of the Howard Hughes Medical Institute.

\section{References}

1. Emery, A. E. H. 1988. Duchenne Muscular Dystrophy. Oxford Medical Publications, Oxford, UK. 317 pp.

2. Moser, H. 1984. Duchenne muscular dystrophy: pathogenic aspects and genetic prevention. Hum. Genet. 66:17-40.

3. Brooke, M. 1986. A Clinician's View of Neuromuscular Diseases. Williams \& Wilkins Co., Baltimore, MD. 388 pp.

4. Boyd, Y., and V. J. Buckle. 1986. Cytogenetic heterogeneity of translocations associated with Duchenne muscular dystrophy. Clin. Genet. 29:108-115.

5. Francke, U., H. D. Ochs, B. de Martinville, J. Giacalone, V. Lindgren, C. M. Disteche, R. A. Pagon, M. H. Hofker, G. J. B. van Ommen, P. L. Pearson, et al. 1985. Minor Xp21 chromosome deletion in a male associated with expression of Duchenne muscular dystrophy, chronic granulomatous disease, retinitis pigmentosa, and McLeod syndrome. Am. J. Hum. Genet. 37:250-267.

6. Davies, K. E., P. L. Pearson, P. S. Harper, J. M. Murray, T. O'Brien, M. Sarfarazzi, and R. Williamson. 1983. Linkage analysis of two cloned DNA sequences flanking the Duchenne muscular dystrophy locus on the short arm of the human X chromosome. Nucleic Acids Res. 11:2303-2312.

7. Kingston, H. M., M. Sarfarazi, N. S. T. Thomas, and P. S. Harper. 1984. Localization of the Becker muscular dystrophy gene on the short arm of the $\mathrm{X}$ chromosome by linkage to cloned DNA sequences. Hum. Genet. 67:6-17.

8. Monaco, A. P., R. Neve, C. Colletti-Feener, C. J. Bertelson, D. M. Kurnit, and L. M. Kunkel. 1986. Isolation of candidate cDNAs for portions of the Duchenne muscular dystrophy gene. Nature (Lond.) 323:646-650.

9. Burghes, A. H. M., C. Logan, X. Hu, B. Belfall, R. G. Worton, and P. N. Ray. 1987. A cDNA clone from the Duchenne/Becker muscular dystrophy gene. Nature (Lond.). 328:434-437.

10. Monaco, A. P., C. J. Bertelson, W. Middlesworth, C. A. Colletti, J. Aldridge, K. H. Fischbeck, R. Bartlett, M. A. Pericak-Vance,
A. D. Roses, and L. M. Kunkel. 1985. Detection of deletions spanning the Duchenne muscular dystrophy locus using a tightly linked DNA segment. Nature (Lond.). 316:842-845.

11. Kunkel, L. M., and 76 coauthors. 1986. Analysis of deletions in the DNA of patients with Becker and Duchenne muscular dystrophy. Nature (Lond.). 322:73-77.

12. Ray, P. N., B. Belfall, C. Duff, C. Logan, V. Kean, M. W. Thompson, J. E. Sylvester, J. L. Gorski, R. D. Schmickel, and R. G. Worton. 1985. Cloning of the breakpoint of an X;21 translocation associated with Duchenne muscular dystrophy. Nature (Lond.). 318:672-675.

13. Fischbeck, K. H., A. W. Ritter, D. L. Tirschwell, L. M. Kunkel, C. J. Bertelson, A. P. Monaco, J. F. Hejtmancik, C. Boehm, V. Ionasescu, M. Pericak-Vance, et al. 1986. Recombination with pERT87 (DXS164) in families with X-linked muscular dystrophy. Lancet. i:104.

14. Monaco, A. P., and L. M. Kunkel. 1987. A giant locus for the Duchenne and Becker muscular dystrophy gene. Trends Genet. 3:33-37.

15. Koenig, M., E. P. Hoffman, C. J. Bertelson, A. P. Monaco, C. Feener, and L. M. Kunkel. 1987. Complete cloning of the Duchenne muscular dystrophy (DMD) cDNA and preliminary genomic organization of the DMD gene in normal and affected individuals. Cell. 50:509-517.

16. Burmeister, M., A. P. Monaco, E. F. Gillard, G. J. B. van Ommen, N. A. Affara, M. A. Ferguson-Smith, L. M. Kunkel, and H. Lehrach. 1988. A 10-megabase physical map of human Xp21, including the Duchenne muscular dystrophy gene. Genomics. 2:189-202.

17. Van Ommen, G. J. B., J. M. H. Verkerk, M. H. Hofker, A. P. Monaco, L. M. Kunkel, P. Ray, R. Worton, B. Wieringa, E. Bakker, and P. L. Pearson. 1986. A physical map of 4 million bp around the Duchenne muscular dystrophy gene on the human X-chromosome. Cell. 47:499-504.

18. Forrest, S. M., G. S. Cross, A. Speer, D. Gardner-Medwin, J. Burn, and K. E. Davies. 1987. Preferential deletion of exons in Duchenne and Becker muscular dystrophies. Nature (Lond.). 329:638640.

19. Hu, X., A. H. M. Burghes, P. N. Ray, M. W. Thompson, E. G. Murphy, and R. G. Worton. 1988. Partial gene duplication in Duchenne and Becker muscular dystrophy. J. Med. Genet. 25:369-376.

20. Hoffman, E. P., R. H. Brown, Jr., and L. M. Kunkel. 1987. Dystrophin: the protein product of the Duchenne muscular dystrophy locus. Cell. 51:919-928.

21. Koenig, M., A. P. Monaco, and L. M. Kunkel. 1988. The complete sequence of dystrophin predicts a rod-shaped cytoskeletal protein. Cell. 53:219-228.

22. Hammond, R. G., Jr. 1987. Protein sequence of DMD gene is related to actin-binding domain of $\alpha$-actinin. Cell. 51:1.

23. Davison, M. D., and D. R. Critchley. 1988. $\alpha$-Actinins and the DMD protein contain spectrin-like repeats. Cell. 52:159-160.

24. Arahata, K., S. Ishiura, T. Ishiguro, T. Tsukahara, Y. Suhara, C. Eguchi, T. Ishihara, I. Nonaka, E. Ozawa, and H. Sugita. 1988. Immunostaining of skeletal and cardiac muscle surface membrane with antibody against Duchenne muscular dystrophy peptide. Nature (Lond.). 333:861-863.

25. Zubrzycka-Gaarn, E. E., D. E. Bulman, G. Karpati, A. H. M. Burghes, B. Belfall, H. Klamut, J. Talbot, R. S. Hodges, P. N. Ray, and R. G. Worton. 1988. The Duchenne muscular dystrophy gene product is localized in the sarcolemma of human skeletal muscle fibres. Nature (Lond.). 333:466-469.

26. Bonilla, E., C. E. Samitt, A. F. Miranda, A. P. Hayes, G. Salviati, S. DiMauro, L. M. Kunkel, E. P. Hoffman, and L. P. Rowland. 1988. Duchenne muscular dystrophy: deficiency of dystrophin at the muscle cell surface. Cell. 54:447-452.

27. Watkins, S. C., E. P. Hoffman, H. S. Slayter, and L. M. Kunkel. 1989. Immunoelectron microscopic localization of dystrophin in myofibres. Nature (Lond.). 333:863-866.

28. Hoffman, E. P., K. Fischbeck, R. H. Brown, M. Johnson, R. 
Medori, J. D. Loike, J. B. Harris, R. Waterston, M. Brooke, L. Specht, et al. 1988. Dystrophin characterization in muscle biopsies from Duchenne and Becker muscular dystrophy patients. N. Engl. J. Med. 318:1363-1368.

29. Hoffman, E. P., L. M. Kunkel, C. Angelini, A. Clarke, M. Johnson, and J. B. Harris. 1989. Improved diagnosis of Becker muscular dystrophy via dystrophin testing. Neurology. 39:1011-1017.

30. Saiki, R. K., D. H. Gelfand, S. Stoffel, S. J. Scharf, R. Higuchi, G. T. Horn, K. B. Mullis, and H. A. Erlich. 1988. Primer-directed enzymatic amplification of DNA with a thermostable DNA polymerase. Science (Wash. DC). 239:487-491.

31. Brooke, M., G. M. Fenichel, R. C. Griggs, J. R. Mendell, R. Moxley, J. P. Miller, M. A. Province, and the CIDD group. 1983. Clinical investigations in Duchenne dystrophy. 2. Determination of the "power" of therapeutic trials based on the natural history. Muscle Nerve. 6:91-103.

32. Zatz, M., M. R. Passos-Buenos, and D. Rapaport. 1989. Estimate of the proportion of Duchenne muscular dystrophy with autosomal recessive inheritance. Am. J. Med. Genet. 32:407-410.

33. Bulman, D. E., E. G. Murphy, E. E. Zubrzycka-Gaarn, R. G. Worton, and P. N. Ray. 1989. Characterization of Duchenne muscular dystrophy patients with antisera which recognize the amino and carboxy-terminal regions of dystrophin. Am. J. Hum. Genet. 45(Suppl.):A179. (Abstr.)

34. Hurko, O., E. P. Hoffman, L. McKee, D. R. Johns, and L. M. Kunkel. 1989. Dystrophin analysis in clonal myoblasts derived from a Duchenne muscular dystrophy carrier. Am. J. Hum. Genet. 44:820826.

35. Arahata, K., E. P. Hoffman, L. M. Kunkel, S. Ishiura, T Tsukahara, T. Ishihara, N. Sunohara, I. Nonaka, E. Ozawa, and H. Sugita. 1989. Dystrophin diagnosis: comparison of dystrophin abnormalities by immunofluorescent and immunoblot analyses. Proc. Natl. Acad. Sci. USA. 86:7154-7158.

36. Darras, B. T., M. Koenig, L. M. Kunkel, and U. Francke. 1988. Direct method for prenatal diagnosis and carrier detection in Duchenne/Becker muscular dystrophy using the entire dystrophin cDNA. Am. J. Med. Genet. 29:713-726.

37. Bakker, E., C. Van Broeckhoven, E. J. Bonten, M. J. Van de Vooren, H. Veenema, N. Van Hul, G. J. B. van Ommen, A. Vandenberghe, and P. L. Pearson. 1987. Germline mosaicism and Duchenne muscular dystrophy mutations. Nature (Lond.). 329:554-556.
38. Darras, B. T., and U. Francke. 1987. A partial deletion of the muscular dystrophy gene transmitted twice by an unaffected male. Nature (Lond.). 329:556-558.

39. Monaco, A. P., C. J. Bertelson, C. Colletti-Feener, and L. M. Kunkel. 1987. Localization and cloning of deletion breakpoints in Xp21 involved in muscular dystrophy. Hum. Genet. 75:221-227.

40. Monaco, A. P., C. J. Bertelson, S. Liechti-Gallati, H. Moser, and L. M. Kunkel. 1988. An explanation for the phenotypic differences between patients bearing partial deletions of the DMD locus. Genomics. 2:90-95.

41. Koenig, M., A. H. Beggs, M. Moyer, S. Scherpf, K. Heindrichs, T. Bettecken, G. Meng, C. R. Muller, M. Lindlof, H. Kaariainen, et al 1989. The molecular basis for Duchenne versus Becker muscular dystrophy: correlation of severity with type of deletion. Am. J. Hum. Genet. 45:498-506.

42. Malhotra, S. B., K. A. Hart, H. J. Klamut, N. S. T. Thomas, S. E. Bodrug, A. H. M. Burghes, M. Bobrow, P. S. Harper, M. W. Thompson, P. N. Ray, et al. 1988. Frame-shift deletions in patients with Duchenne and Becker muscular dystrophy. Science (Wash. DC). 242:755-759.

43. Chamberlain, J. S., R. A. Gibbs, J. E. Ranier, P. N. Nguyen, and C. T. Caskey. 1988. Deletion screening of the Duchenne muscular dystrophy locus via multiplex DNA amplification. Nucleic Acids Res. 16:11141-11156.

44. Roberts, R. G., C. G. Cole, K. A. Hart, M. Bobrow, and D. R. Bentley. 1989. Rapid carrier and prenatal diagnosis of Duchenne and Becker muscular dystrophy. Nucleic Acids Res. 17:811.

45. Weber, J. L., and P. E. May. 1989. Abundant class of human DNA polymorphisms which can be typed using the polymerase chain reaction. Am. J. Hum. Genet. 44:388-396.

46. Oudet, C., R. Heilig, and J. L. Mandel. 1990. An informative polymorphism detectable by polymerase chain reaction at the $3^{\prime}$ end of the dystrophin gene. Hum. Genet. In press.

47. Beggs, A. H., and L. M. Kunkel. 1990. Improved detection of polymorphism at a CACA repeat in the $3^{\prime}$ untranslated region of dystrophin. Nucleic Acids Res. In press.

48. Richards, C. S., I. W. Milsark, E. P. Hoffman, S. C. Watkins, N. Schneider, K. S. Katz, J. D. Cook, L. M. Kunkel, and J. M. Cortada. 1990. Nonrandom lyonization results in Duchenne muscular dystrophy in a monozygotic twin female. Am. J. Hum. Genet. In press. 